\title{
Minimizing Power Loss Using Modified Artificial Bee Colony Algorithm
}

\author{
Nur Azlin Ashiqin Mohd Amin ${ }^{1}$, Siti Hafawati Jamaluddin'², Nur Syuhada Muhammat Pazil ${ }^{3}$, Norwaziah \\ Mahmud $^{4}$, Norhanisa Kimpol ${ }^{5}$ \\ 1,2,4 Faculty of Computer and Mathematical Sciences, \\ Universiti Teknologi MARA Perlis Branch, Arau Campus, 02600 Arau, Perlis, Malaysia \\ ${ }^{3}$ Faculty of Computer \& Mathematical Sciences, Universiti Teknologi MARA, 77300 Jasin Melaka, Malaysia \\ ${ }^{5}$ Universiti Malaysia Perlis
}

Corresponding author: *hafawati832@uitm.edu.my

Received Date: 22 June 2021

Accepted Date: 22 July 2021

Published Date: 1 September 2021

\section{HIGHLIGHTS}

- Modified Artificial Bee Colony Algorithm was used to determine the minimum power loss.

- The standard IEEE-30 bus test system was tested in finding the minimum value of power loss.

- The obtained results have been compared with Firefly Algorithm and Artificial Bee Colony Algorithm.

\begin{abstract}
Electrical energy losses are found in any part of the power system. In the power system, it is essential to minimize the real power loss in transmission lines. The voltage deviation at the load buses through controlling the reactive power flow is very important. This ensures the secured operation of power systems regarding voltage stability and the economics of the process due to loss minimization. In this paper, the Modified Artificial Bee Colony (MABC) algorithm is implemented to solve the power system's optimal reactive power flow problem. Generator bus voltages, transformer tap positions, and settings of switched shunt of compensators are used as decision variables to control the reactive power flow. These control variable values are adjusted for loss reduction. MABC algorithm is tested on the standard IEEE-30 bus test system. The results are compared with Firefly algorithm (FA) and Artificial Bee Colony (ABC) algorithm method to prove the effectiveness of the newest algorithm. The power loss results are quite productive, and the algorithm is the most efficient than the other methods such as ABC algorithm and FA algorithm. These results are produced by Matlab $2017 \mathrm{~b}$.
\end{abstract}

Keywords: Modified Artificial Bee Colony (MABC) algorithm, electrical energy, power loss, power system.

\section{INTRODUCTION}

Electricity is most critical to our daily existence. Almost complete of the device at home, companies, and industries are used because of electricity. So, we will see that the demand for electrical strength has boomed globally. Electric powered energy is typically produced via electrically powered mills. However, additionally, it may be supplied through resources that include electric powered batteries. It also includes supply to groups and houses via electric strength enterprise through an electric strength grid. The electric strength grid is one example of an electric power gadget that offers electricity to an extended place. 
Electric power gadget is a community of electrical deployed to supply, transfer and use electric strength. Monti and Ponci (2015) said that electric power machine is a large infrastructure, and it is a complicated operation on society and other infrastructures. The transmitted powers are misplaced all through the manner to the surroundings due to the fact over utilization. The significance of electrical energy cannot be overemphasized since it holds the key for energy resources in business and home activities. The most reliable value of electrical energy is vital to the advancement of civilization.

Aside from that, in line with the Anumaka (2012), losses in electric energy gadgets can be diagnosed as the loss due to inner elements and external elements, which the inner component called technical losses and the external element is known as non-technical losses. Consequently, reduction of system losses could be very significant to the software organization's economic, financial, and socioeconomic values, customers, and the host country. To reduce the losses in the transmission machine, the generating station will be installed near the weight centers because power loss is beneficial to enhance the voltage profile and reduce the device power losses.

Sankaramoorthy and Veluchamy (2017) said that the electrical strength distribution distributes electric strength to the end customers. There's a distribution gadget in the power system that is one a part of the power machine that distributes the strength to stop customers from utilization. Dixit et al. (2014) state that the current structures with loaded traces can result in the power system. Its function is to give a better voltage deviation and a higher strength loss. It can be carried out about insecure operation of strength gadgets. The especially due to continuous, uncertain increase and demand of electrical power is the reasons.

\section{METHODOLOGY}

\section{Power Loss}

Deenadhayalan (2014) has proposed Firefly Algorithm (FA) to minimize power loss for achieving Optimal Reactive Power Dispatch (ORPD). Denenadhayalan also said that to quickly implement for any optimization problems and fewer operators in FA. FA brings a better optimal power loss and voltage deviation compared to Biogeography-based Optimization (BBO) algorithm since the result obtained is more efficient and high-quality. Meanwhile, Singh et al. (2017) have proposed Particle Swarm Optimization (PSO) to minimize the power loss in the power system. They stated that the PSO algorithm has a better performance than others since this algorithm gives a good result in reducing higher order in losses compared to other algorithms.

The objective function of power loss is determined in Eq. (1) (Deenadhayalan, 2012).

$$
f=\min \left(P_{L}\right)
$$

where $P_{L}$ is total real power which $P_{L}$ can be defined as follows:

$$
P_{L}=\sum_{k=1}^{N_{L}} G_{K}\left[V_{i}^{2}+V_{j}^{2}-2 V_{i} V_{j} \cos \left(\delta_{i} \delta_{j}\right)\right]
$$


where $N_{L}$ is the total number of lines in the system, $G_{K}$ is the conductance of the line $k, V_{i}$ and $V_{j}$ are the magnitudes of the sending end and receiving end voltages of the lines, $\delta_{i}$ and $\delta_{j}$ are angles of end voltages,

$$
\begin{aligned}
& G_{K}=\frac{1}{V_{i}} \\
& V_{j}=x\left[\frac{P}{V_{i} \sin (\delta)}\right]
\end{aligned}
$$

where $\mathrm{P}$ is the real power, $\mathrm{x}$ is the line impedance.

\section{Artificial Bee Colony Algorithm}

Rao et al. (2008) stated that Artificial Bee Colony (ABC) algorithm is a metaheuristic approach by honeybee swarm as a new population. They stated that the $\mathrm{ABC}$ algorithm has some advantages where this algorithm does not involve the external parameter, for example, mutation, cross over rate, and differential evolution in genetic algorithm. In addition, the global search in the ABC algorithm is to uses the same neighborhood resource mechanism with the mutation process.

A few obligations are performing by using specialized individuals in an actual bee colony. Those specialized bees try and maximize the nectar amount in the hive using efficient division of labor and selfagency. The selection of honey bee colony consists of 3 types of bees such as hired bees, onlooker bees, and scout bees. Hired bees are answerable for exploiting the nectar resources explored earlier than and giving the statistics to the ready bees (onlooker bees) within the hive about the best food source websites they're exploiting. Onlooker bees wait inside the hive and decide on a food source to take advantage of based on the records shared by the hired bees. Scout randomly seeks the surroundings to discover a new food source supply relying on internal motivation (Akay and Karaboga 2012).

Suppose the search is regarded as a nest environment that contains a food source site. In that case, this algorithm begins by randomly generating site feed resources that correspond to the solution in space search. Source of startup the feeds are generated randomly within the boundary parameter environment.

$x_{i j}=x_{j}^{\min }+\operatorname{rand}(0,1)\left(x_{j}^{\max }-x_{j}^{\min }\right)$

where $i=1, \ldots, S N, j=1, \ldots, D . S N$ is the number of food sources, and $D$ is the number of optimization parameters.

Each bee used is related to only one source of source food. Therefore, the number of food source sites is the same as the number of bees used. The bee used produced changes to the food source (solution) position in bee memory depending on the information (visual information) and find the source of the neighbor's food and then assess its quality.

$v_{i j}=x_{i j}+\phi_{i j}\left(x_{i j}-x_{k j}\right)$

where $\mathrm{j}$ is a random integer in the range $[1, \mathrm{D}]$ and $\mathrm{k} \in[1,2, \ldots, \mathrm{SN}]$ is a randomly chosen index that has to be different from $i$ and $\phi_{i j}$ is a uniformly distributed real random number in the range $[-1,1]$. 
After all the hired bees finish solving their quest, they share information about the number of nectar and their source position with the onlooker bee in the dance area. These are various characteristics of bee imagination. An onlooker will evaluate the information of nectar taken from all the bees performed and select the source of the food source with the probability associated with the amount of nectar. This probabilistic selection depends on the value fitness solution in the population. However, in this study, roulette wheel selection is used as in Eq. (7).

$$
P_{i}=\frac{\text { fitness }_{i}}{\sum_{i=1}^{S N} \text { fitness }_{i}}
$$

A random real number within the range $[0,1]$ is generated for each source in the $\mathrm{ABC}$ algorithm. Once the source is assessed, greedy selections are used, and bees thinking either memorize new positions by forgetting the old ones or keeping the old ones where the trial stop counts are executed by 1 , if $x_{i j}$ cannot be fixed otherwise, the counter is reset 0 . This process is repeated until all onlookers are distributed to the source of the food source.

\section{Modified Artificial Bee Colony Algorithm}

Sulaiman et al. (2013) stated the modified ABC algorithm (JA-ABC) is to increase the capabilities of residents by deciding on a poor solution since $\mathrm{ABC}$ algorithm has only one "limit" parameter other than the standard parameter-based control algorithm such as population size or colony size (SN) and maximum generation number or maximum cycle number (MCN).

$\mathrm{ABC}$ algorithm is very effective for multimodal and multidimensional basic functions. However, the convergence rate of the algorithm is worse when working with constrained problems, composite functions, and some non-separable function. The issue was increased from stochastic variation in which a new solution derived from competition. In this process, some research of parameters such as perturbation frequency or magnitude of the perturbation is important since they affect the division of new solutions. To improve rate convergence, some modifications have been introduced in the $\mathrm{ABC}$ algorithm perturbation process. This process will focus on fitting the diverse population by controlling the frequency of perturbation.

In $\mathrm{ABC}$ algorithm, this frequency is fixed. While producing a new solution in $\mathrm{ABC}$ algorithm, $v_{i j}$ is the changing that only one parameter of the parent solution $x_{i j}$ results in a slow convergence rate. The $\mathrm{ABC}$ algorithm is modified by introducing parameter control and Modification Rate (MR) to overcome this problem. By doing this modification, a uniformly distributed random number in the range [-1,1] is produced for each parameter $x_{i j}$. If the random number is less than MR, then the parameter $x_{i j}$ is modified as follow:

$v_{i j}=\left\{\begin{array}{cc}x_{i j}+\phi_{i j}\left(x_{i j}-x_{k j}\right), & \text { if } \mathrm{R}_{\mathrm{ij}}<M R \\ x_{i j}, & \text { otherwise }\end{array}\right.$

where $k \in\{1,2, \ldots, S N\}$ is randomly chosen index that has to be different from $i$ and $M R$ is the rate of modification taking between 0 and 1 . A lower value of $M R$, whereas $M R=0.4$ will cause the solutions to improve slowly, while a higher one may cause too much diversity in a solution and hence in the population.

The flowchart of modified ABC algorithm is shown below. 


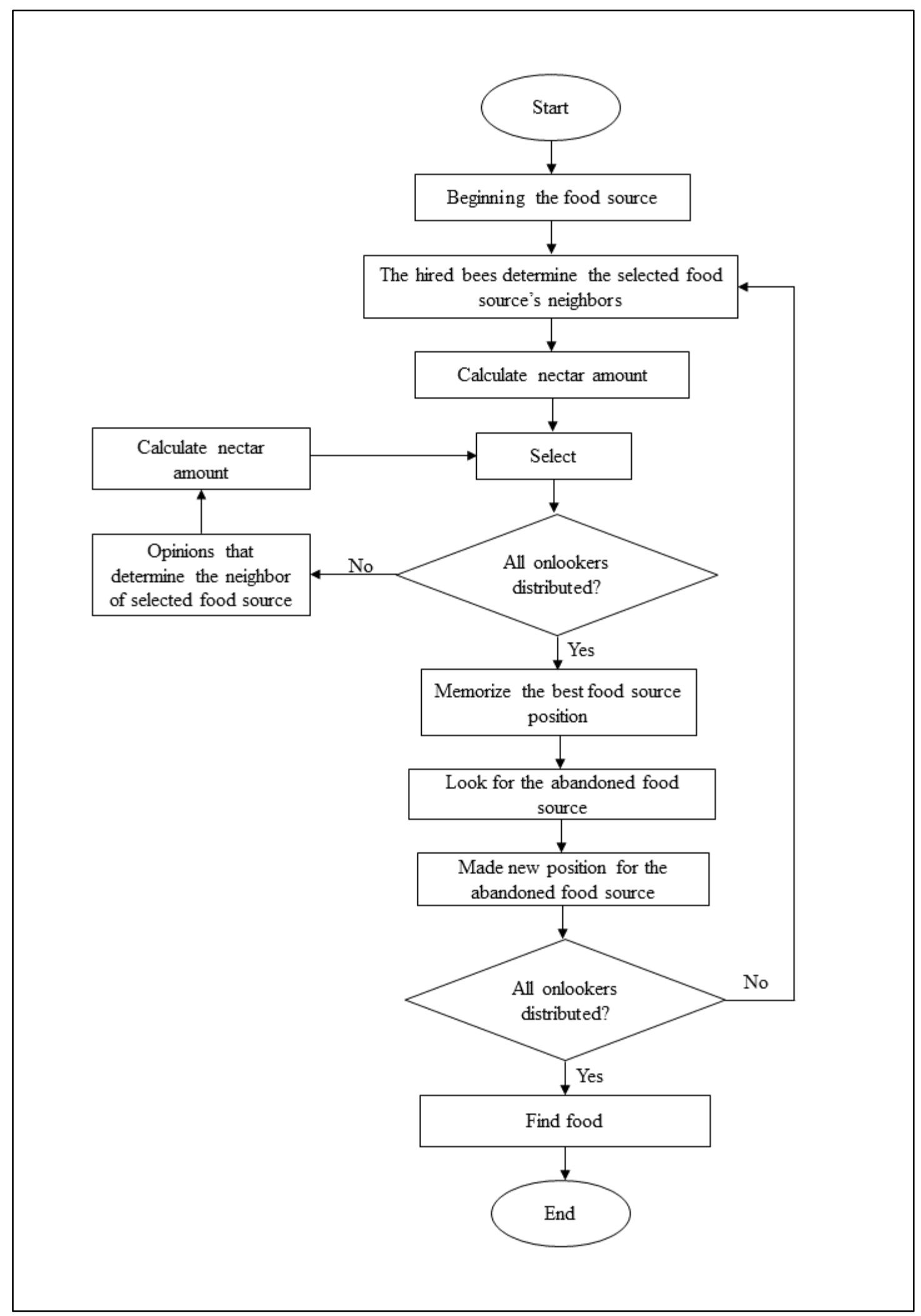

Figure 1: Flowchart of Modified ABC Algorithm 


\section{FINDINGS AND DISCUSSIONS}

A set of data are adopted from Deenadhayalan (2014) where the data contains three control variables which are generator bus voltage magnitudes, transformer tap settings, and volt-ampere reactive (VAR) outputs from shunt compensating devices. The value of the upper bound and lower bounds of the different control variables are given in Table 1.

Table 1: Boundary of Each Dataset

\begin{tabular}{|l|c|}
\hline \multicolumn{1}{|c|}{ Control Variable } & Limit \\
\hline Generator Voltage, $V_{G I}$ & $(0.9-1.1)$ per unit \\
\hline Tap Setting, $T_{P I}$ & $(0.9-1.1)$ per unit \\
\hline MVAR by Static Compensator, $Q_{S V C}$ & $(0-10)$ MVAR \\
\hline
\end{tabular}

IEEE-30 bus system is used to find the minimum value of power loss. There are four of the tap changing transformers in this bus system, which are connected between the bus numbers 6-9, 6-10, 4-12, and 27-28. At the same time, two shunts of compensators are also connected in the bus numbers of 10 and 24. The illustration of IEEE-30 bus system is shown in Figure 2.

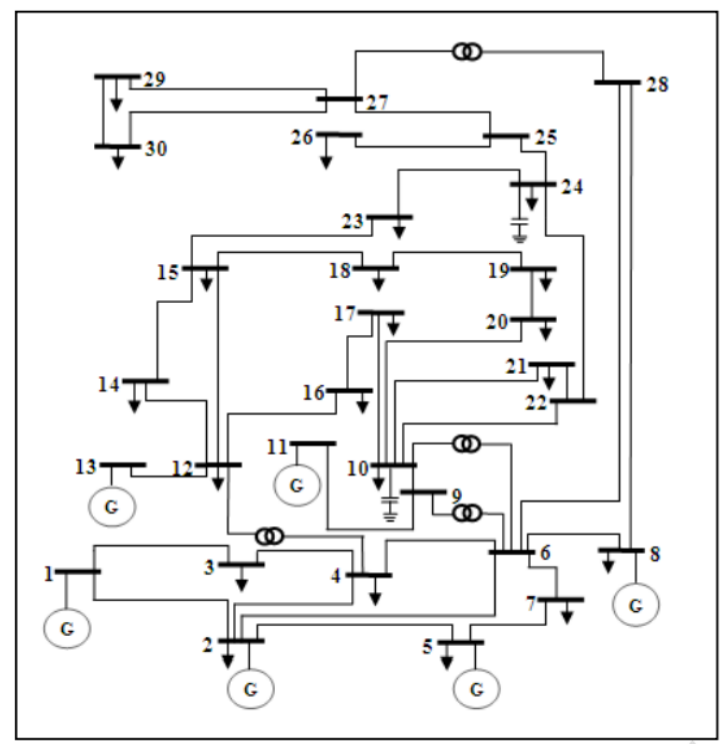

Figure 2: Single Line of IEEE-30 Bus System (Source: IEEE 30-Bus System, 2018)

The optimal values for the control variables used in real power loss are achieved in real power loss minimization are shown in Table 2. 
Table 2: Optimal Parameter Values

\begin{tabular}{|c|c|}
\hline Parameter & $\begin{array}{c}\text { Optimal value } \\
\text { (MABC) }\end{array}$ \\
\hline VG1 & 0.9804 \\
\hline VG2 & 0.9152 \\
\hline VG5 & 0.9480 \\
\hline VG8 & 0.9247 \\
\hline VG11 & 0.9368 \\
\hline VG13 & 0.9480 \\
\hline T6-9 & 0.9835 \\
\hline 76-10 & 0.9099 \\
\hline T4-12 & 1.0805 \\
\hline T27-28 & 1.0890 \\
\hline Q10 & 4.9086 \\
\hline Q24 & 0.8925 \\
\hline
\end{tabular}

Based on the results obtained in Table 2 above, the minimum value of power loss is determined, which value is 4.4333 , by substituting all the obtained values in Table 2 into Eq. (2).

Table 3: Minimum Value Power Loss of MABC Algorithm, ABC Algorithm, and FA

\begin{tabular}{|c|c|c|}
\hline MABC & ABC & FA \\
\hline 4.4333 & 4.5194 & 4.7106 \\
\hline
\end{tabular}

Table 3 above shows minimum power loss by using MABC algorithm, $\mathrm{ABC}$ algorithm, and FA. From that, it can be concluded that the MABC algorithm performs better than $\mathrm{ABC}$ algorithm and $\mathrm{FA}$.

\section{CONCLUSION}

In conclusion, the performance of the Modified Artificial Bee Colony (MABC) algorithm for solving optimal real power flow problems is explained using the IEEE-30 bus system to get the minimum value of the power loss. The results had been proven. These results are compared with other algorithms like ABC and FA algorithm. The results showed that MABC is more effective compared to basic $\mathrm{ABC}$ and FA algorithm approaches and high quality solutions. Since the power loss obtained gives a better performance, then the electrical supplier can use the optimal value of each parameter found.

\section{REFERENCES}

Akay, B., \& Karaboga, D. (2012). A modified artificial bee colony algorithm for real-parameter optimization. Information Sciences, 192, 120-142.

Anumaka, M. C. (2012). Analysis oftechnical losses in electrical power system (Nigerian 330KV network as a case study). Technical Losses in Electrical Power System, 12(2), 320-327.

Baskar, S., \& Pooja, S. (2017). Minimization of real power loss using genetic algorithm. Journal of Invention in Computer Science and Communication Technology (JICSCT), 3(6), 1-10. 
Deenadhayalan, M. H. (2014). Real power loss minimization using firefly algorithm. IJAICT, 1(8), 667682.

Dixit, S., Srivastava, L., \& Agnihotri, G. (2014). Minimization of power loss and voltage deviation by SVC placement using GA. International Journal of Control and Automation, 7(6), 95-108.

Monti, A., \& Ponci, A. (2015). Electric power system. Springer-Verlag Berlin Heidelberg, 12, 31-65.

PSCAD. (2018). IEEE 30 Bus System.

Rao, R. S., Narasimham, S. V. L., Ramalingaraju, M. (2008). Optimization of distribution network configuration for loss reduction using artificial bee colony algorithm. International Scholarly and Scientific \& Innovation, 2(9), 1964-1970.

Sankaramoorthy, M., \& Veluchamy, M. (2017). A hybric MACO and BFOA algorithm for power loss minimization and total cost reduction in distribution systems. Turkish Joutnal of Elecrtrical Engineering \& Computer Sciences, 25, 337-351.

Singh, S., Jain, V. K., \& Prasad, U. (2017). Power loss reduction in power system based on PSO: case study. International Journal of Computer Application, 164(10), 22-26.

Sulaiman, N., Mohammad-Salleh, J., \& Abro, A. G. (2013). A modified artificial bee colony (ja-abc) optimization algorithm. International Conference on Applied Mathematics and Computational Method in Engineering, 74-79. 